American Journal of Primatology 73:503-506 (2011)

\title{
INTRODUCTION
}

\section{Understanding Emotions in Primates: In Honor of Darwin's 200th Birthday}

\author{
DOROTHY FRAGASZY* AND ELIZABETH SIMPSON \\ University of Georgia, Athens, Georgia
}

In the bicentenary year of Darwin's birth, the American Society of Primatologists honored his memory by convening a symposium entitled "Understanding emotions in primates: In honor of Darwin's 200th birthday." The four articles in this special section, excepting this introduction, derive from that symposium. The section confirms that the topic of emotion is once again, as in Darwin's lifetime, the subject of wide-ranging, theoretically exciting research, and that studies with nonhuman primates are at the leading edge of a rapidly changing field. Am. J. Primatol. 73:503-506, $2011 . \quad$ (c) 2011 Wiley-Liss, Inc.

\section{Key words: health; behavior; coping; well-being}

In 2009, the world celebrated Darwin's contributions to science on the bicentenary of his birth in 1809. Every student of biology knows that Charles Darwin published On the Origin of Species in 1859, and that the theory of evolution that he advocated in this slim volume generated vigorous debate among the scientific community, the clergy, and the general public in Britain and beyond for many years following -indeed, to the present day. We are all familiar with the basic tenets of Darwin's theory of evolution, including the linked hypotheses that diverse forms of life arise through natural selection acting upon heritable variations, and thus that contemporary diversity reflects historical continuity. Darwin made clear that this interpretation of biological diversity applied to humans, and posited a refined model of selection to account for certain characteristics of sexually reproducing species, in a second great volume, The Descent of Man and the Selection in Relation to Sex, published in 1871. Within days of finishing the page proofs for this book, he began work on his final book concerning humans, The Expression of the Emotions in Man and Animals, and finished it in a mere 4 months [Ekman, 1998]. This book appeared in 1872, and like his two previous books, it was an immediate best seller.

In The Expression of the Emotions of Man and Animals (1872; now in its fourth edition, 2009), Darwin established emotion as a proper topic of scientific study from a biological perspective, and he argued that humans display, in their expressions of emotion as in other aspects of their biology, their shared ancestry with other animals. He also proposed that emotions are discrete, that the face is particularly expressive of emotions, and that facial expressions of emotion in humans are universal. Although scientific scrutiny and public debate of the general theory of evolution has continued at a feverish pitch ever since On the Origin of Species appeared, and the theory of sexual selection likewise has been developed extensively in modern evolutionary theory, Darwin's last great treatise concerning humans and human behavior has received far less attention. Paul Ekman, in the introduction to the 3rd edition of The Expression, writes “... [U]ntil very recently the book had been studiously ignored. Yet it was a bestseller when it was published in England in 1872. Nine thousand copies were sold in the first four months. By the turn of the century it had also been published in the United States, the Netherlands, France, Germany, and Russia. ... Today scientist and layman alike know who Darwin is, but not his book on expression. Many biologists do not even know that Darwin wrote such a book..." [Ekman, 1998; p xxix]. Indeed, for most of the century after Darwin wrote about expression, his views were rejected or simply ignored.

Although the topic of emotion seems to have languished in the doldrums of the sea of science for close to a century, it has resurfaced in recent decades, and Darwin's singular contribution to this area of science is now better appreciated. Historians of science may point to many threads of thinking and evidence that supported this change. We like to think that the persistent effort of researchers studying the behavior of nonhuman primates played a role in this renaissance. Thus, it seemed fitting, on the bicentenary of Darwin's birth, to honor him by treating

\footnotetext{
*Correspondence to: Dorothy Fragaszy, Department of Psychology, University of Georgia, Athens, GA 30602.

E-mail: dfragaszy@gmail.com

Received 21 December 2010; revision accepted 22 December 2010

DOI 10.1002/ajp.20933

Published online 15 February 2011 in Wiley Online Library (wiley onlinelibrary.com).
} 
the topic of emotions to a thoroughly public consideration, to see in some measure where we have been and where we are going in our efforts to understand emotions in primates. For this purpose, the American Society of Primatologist convened a symposium at our 2009 meeting entitled "Understanding emotions in primates: In honor of Darwin's 200th birthday." The symposium opened with a major address by a featured speaker, J. Panksepp, and continued with four additional presentations.

\section{STUDYING EMOTIONS AND PHYSIOLOGICAL SYSTEMS THAT SUBSERVE THEM}

We take as our starting point Darwin's conclusions that emotions in humans and nonhuman mammals reveal shared ancestry and function, and that emotions are in many dimensions qualitatively similar across mammals. More specifically, basic emotions-SEEKING, RAGE, FEAR, LUST, maternal CARE, separation distress PANIC/GRIEF, and physical PLAY [Panksepp, 2011, this issue]-are shared widely among mammals, and likely among an even wider array of species. Conditions or circumstances that increase positive emotions-friendships, good food, status, attractive mates, safe and comfortable shelter, caring for offspring-are things that aid in our survival and reproduction. Experiences and stimuli that increase negative emotionssocial rejection, predators, rotten food, and diseaselikewise affect survival and reproduction. For example, humans' attention, and likely other animals' attention as well, is captured relatively easily by threatening stimuli (e.g., loud noise, angry face). For many animals-including humans-social interactions with conspecifics are of utmost importance. Social animals interpret the emotional signals (facial expressions, vocal expressions, postures) of conspecifics. Situations that compromise social connections temporarily enhance social perception in humans, and may do so in other animals as well. For example, in humans, increasing feelings of social rejection improve the ability to recognize whether an expression (e.g., smile) is genuine or artificial, a characteristic which is proposed to facilitate affiliation [Bernstein et al., 2008].

Given shared ancestry and shared function, emotion, such as other features of the organism, can be profitably studied from an evolutionary and comparative perspective. For data on diverse species to be interpretable within a comparative framework, it is important to have standardized methods of assessing emotion and useful to have multiple measurement tools for a given assessment. Fortunately, we have a variety of methods that are appropriate for studying physiological underpinnings of emotions in many species. For example, select regions of the brain can be stimulated or blocked from activity to measure behavioral or other consequences [e.g., Krack et al., 2010]. The timing of larger scale (i.e., structures, systems) brain activity can be measured indirectly using electroencephalogram, and locations of brain activity can be measured indirectly using functional magnetic resonance imaging [e.g., Hoffman et al., 2007]. Physiological measures of autonomic arousal have been used with both human and nonhuman animals, and include measures of facial temperature (e.g., nose temperature in nonhuman primates), heart rate, respiration, skin conductance, pupil dilation, eye blinks, and startle responses [e.g., Reefmann et al., 2009]. We can link behavioral indices of emotion (e.g., a particular component of maternal behavior) with a neurochemical state, as measured by titers of neurotransmitters, hormones, or certain proteins [e.g., Campbell, 2010; Grigoriev et al., 2003]. Single cell recordings can directly measure neural activity in response to emotional stimuli [e.g., Maior et al., 2010].

Precise behavioral measures are available for studies with humans and other animals, and provide another dimension for comparison across species. For example, the movements or activations of facial musculature can be measured using facial electromyography. Sometimes, such muscle movements are not visible to the naked eye, yet can be measured with this equipment and provide information about emotional responses and emotional interpretations. The facial action coding system has been employed with human and nonhuman primates [e.g., Vick et al., 2007]. On a larger scale, one can quantify body postures, or approach and avoidance movements, and preferences. Thus, even though paradigms that rely on verbal report are relevant only to humans, we have many ways to study emotion comparably across species.

\section{OVERVIEW OF THE SPECIAL SECTION}

This special section contains contributions by four presenters in the 2009 symposium (J. Panksepp, J. Capitanio, D. Maestripieri, and M. Owren). J. Panksepp [2011] recounts the history of the neuroscientific study of behavior to illustrate how, until very recently, emotions in nonhuman animals were set aside as improper subjects of research. We now know from decades of careful scientific inquiry that emotional experience in humans, as in all other mammals, does not depend upon cortical interpretation of bodily states; rather, emotional experiences in humans arise from the same (i.e., homologous) subcortical neural networks as in all mammals that have been studied closely, reconfirming Darwin's intuitive understanding of continuity of emotional process across species (at least, across mammals). The neuroscientific evidence clearly shows that emotion is directly experienced (in Panksepp's words, "primary process"). Panksepp [2011] suggests that we are now positioned to connect psychodynamics (aspects of brain function that are experienced) to the neurodynamics of the 
brain. A challenge for contemporary neuroscience is to study primary-process affective experiences in all mammals (both positively and negatively valenced experiences) and, in this way, better understand the nature of human psychiatric disorders.

Capitanio [2011] shows how Panksepp's call to examine both positively and negatively valenced emotions in nonhuman primates can yield advances in understanding health in a broad sense. He reviews evidence that temperament mediates individual differences in health in captive rhesus monkeys. Capitanio [2011] points to sociability (a general tendency to affiliate with others) as a feature of temperament associated with positive affect and with sensitivity of brain systems to dopamine. Capitanio [2011] shows that sociability has both direct and indirect effects on monkeys' health, and that those indirect effects are mediated by how well individuals fit the situations in which they find themselves. As Panksepp [2011] suggested would be the case, this insight about emotion informs our understanding of health and coping in humans and in nonhuman primates.

Maestripieri [2011] looks at a complex set of emotional processes relevant to maternal behavior in rhesus monkeys. Under normal circumstances, maternal behavior in mammals waxes and wanes in predictable ways in concert with infants' needs for protection and nourishment. However, individuals vary considerably from one another in maternal behavior, as well as in general temperament. Emotional reactivity is an important regulator of maternal behavior. Individual differences in emotional reactivity also correspond with individual differences in susceptibility to stress. Maestripieri [2011] reviews how emotional reactivity and stress interact to affect maternal behavior in rhesus monkeys, a topic that calls out for further research. Furthermore, he points out that some negatively valenced features of Pryce's [1992] widely cited model of maternal motivation in mammals seem not to be present in normally reared rhesus monkeys, but rather are evident only in atypically reared rhesus monkeys. This finding marks an apparent important difference in maternal motivation between primates and rodents, and one that warrants careful scrutiny for the advancement of theory in this area.

Owren et al. [2011] address the role of emotion (affect) in vocalizations of monkeys and apes, and the extent to which vocalizations can be voluntarily modulated, topics of abiding relevance to the evolution of language. They propose two principles, one concerning development and the other concerning neural pathways, which characterize vocalizations across species, and they use these principles to interpret a broad literature concerning vocal flexibility in primates. The first principle is that there are two patterns of vocal development, "production first" and "reception first." The second principle concerns the neural pathways associated with vocal production. Affectively triggered vocalizations share the same neural pathway across mammals, involving subcortical structures in the limbic system. However, a functionally distinct vocal capacity to produce novel sounds, present in humans and perhaps present in rudimentary form in great apes, is associated with a second, cortically based neural pathway. The second pathway has counterparts in orders other than primates (e.g., bats and song birds, and perhaps some marine mammals), suggesting convergent evolution. Owren et al. suggest that affectively triggered vocalizations develop in the productionfirst manner, whereas language develops in the reception-first manner. According to this framework, experience can play a different role in the development of the two kinds of systems. The authors interpret almost all the evidence for vocal flexibility in nonhuman primates as concordant with a production-first, affectively triggered system, which is shared with humans, as Darwin proposed. This interpretation differs importantly from the conventional view of many researchers in this area that instead view elements of vocal flexibility in nonhuman primates as shared with human language. As in matters of health and maternal behavior, much about the role of affect in vocal communication in primates remains to be investigated.

\section{FUTURE DIRECTIONS}

The articles in this special section have presented an array of fundamental topics, including health, maternal behavior, social development, and communication, in which research with nonhuman primates has already provided insights into the role of emotions in biology. And, there is a bright future for continuing research in emotions, both with respect to basic biology and to medicine, as Panksepp [2011] reminds. For example, characterizing individual differences in emotionality, understanding emotional expressions in others, and the developmental and experiential origins of these differences are important challenges. Another major challenge, in the neurobiology of emotion, is to understand emotional processes. We are increasingly informed about the neural structures involved in emotions, but much less so about the processes that take place, nor about direct and indirect influences of these processes on the rest of the brain.

It is clear that the body, in addition to the brain, participates in the perception of others actions, including emotional expressions. For example, recent work with humans has found that body posture (e.g., supine position) and facial posture (e.g., holding a pencil between teeth) can each influence the perception of emotional stimuli, one's emotional state, and emotional brain activation [e.g., Davis et al., 2010]. It would be interesting to explore whether similar modulation of emotion recognition occurs in 
nonhuman primates. Another rich avenue to explore in comparative research is the role of the mirror neuron system [Rizzolatti \& Craighero, 2004] in emotional responsiveness in various species. For example, in humans, a match between an observer's posture and a target's emotional expression facilitates emotional understanding [Niedenthal, 2007].

Better understanding of emotions in nonhuman primates can improve their care and management, thus improving their health and well-being. It is our ethical responsibility to provide for their well-being and this includes promoting positive emotional states. In addition, providing maximal well-being for captive animals in research is cost-effective. Emotionally healthy animals are more successful at reproducing, live longer and with fewer health complications, and provide better quality data.

Though emotions research historically has focused on negative emotions in nonhuman animals, a paradigm shift is underway, as is evident in all the articles in this section. We now realize that we need to study emotions in all animals in a balanced way, with equal attention to positively and negatively valenced emotions. Thus, we can expect to see our models and our studies of emotion in nonhuman animals expand to include play, social bonding, joy, and other positive emotions. That is a pleasant thought, as well as good science.

\section{REFERENCES}

Bernstein MJ, Young SG, Brown CM, Sacco DF, Claypool HM. 2008. Adaptive responses to social exclusion: social rejection improves detection of real and fake smiles. Psychological Science 19:181-983. DOI: 10.1111/j.1467-9280.2008.02187.x.

Campbell A. 2010. Oxytocin and human social behavior. Personality and Social Psychology Review 14:281-295. DOI: $10.1177 / 1088868310363594$.

Capitanio JP. 2011. Individual differences in emotionality: social temperament and health. American Journal of Primatology 73:507-515.

Darwin C. 2009. The expression of emotions in man and animals. Oxford: Oxford University Press. Fourth edition. First published 1872, John Murray, London.
Davis JI, Senghas A, Brandt F, Ochsner KN. 2010. The effects of BOTOX injections on emotional experience. Emotion 10:433-440. DOI: 10.1037/a0018690.

Ekman P. 1998. Introduction to the third edition. In: Darwin C, editor. The expression of emotions in man and animals. Third edition. Oxford: Oxford University Press.

Grigoriev IV, Nikolaeva LV, Artamonov ID. 2003. Protein content of human saliva in various psychoemotional states. Biochemistry 68:405-406. DOI: 10.1023/ A:1023695729019.

Hoffman KL, Gothard KM, Schmid MC, Logothetis NK. 2007. Facial-expression and gaze-selective responses in the monkey amygdala. Current Biology 17:766-772. DOI: 10.1016/ j.cub.2007.03.040.

Krack P, Hariz M, Baunez C, Guridi G, Obeso JA. 2010. Deep brain stimulation: from neurology to psychiatry? Trends in Neuroscience 33:474-484. DOI: 10.1016/j.tins. 2010.07.002.

Maestripieri D. 2011. Emotions, stress, and maternal motivation in primates. American Journal of Primatology 73:516-529.

Maior RS, Hori E, Tomaz C, Ono T, Nishijo H. 2010. The monkey pulvinar neurons differentially respond to emotional expressions of human faces. Behavioural Brain Research 215:129-135. DOI: 10.1016/j.bbr.2010.07.009.

Niedenthal PM. 2007. Embodying emotion. Science 18:1002-1005. DOI: 10.1126/science.1136930.

Owren M, Amoss T, Rendall D. 2011. Two organizing principles of vocal production: implications for nonhuman and human primates. American Journal of Primatology 73:530-544.

Panksepp J. 2011. Toward a cross-species neuroscientific understanding of the affective mind: do animals have emotional feelings? American Journal of Primatology 73:545-561.

Pryce CR. 1992. A comparative systems model of the regulation of maternal motivation in mammals. Animal Behaviour 43:417-441. DOI: 10.1016/S0003-3472(05)80102-2.

Reefmann N, Wechsler B, Gygax L. 2009. Behavioural and physiological assessment of positive and negative emotion in sheep. Animal Behaviour 78:651-659. DOI: 10.1016/j.anbehav. 2009.06.015.

Rizzolatti G, Craighero L. 2004. The mirror-neuron system. Annual Review of Neuroscience 27:169-192. DOI: 10.1146/ annurev.neuro.27.070203.144230.

Vick S, Waller BM, Parr LA, Smith-Pasqualini MC, Bard KA. 2007. A cross-species comparison of facial morphology and movement in humans and chimpanzees using the Facial Action Coding System (FACS). Journal of Nonverbal Behavior 31:1-20. DOI: 10.1007/s10919-006-0017-z. 